\title{
Boltvinik, Julio y Araceli Damián (coords.), La pobreza en México y el mundo. Realidades \\ y desafios, México, Siglo XXI*
}

\section{Martha Schteingart**}

El libro La pobreza en México y el mundo, coordinado por Julio Boltvinik y Araceli Damián, es producto de la recopilación de algunos de los materiales presentados en el Coloquio Internacional "Pobreza, realidad y desafío", que tuvo lugar en septiembre de 2003 en Ciudad Victoria, Tamaulipas, y cuyo objetivo fue congregar a un amplio grupo de especialistas en pobreza y políticas sociales para evaluar y discutir la situación actual de estos temas a nivel regional, internacional y nacional.

El volumen, de más de 500 páginas, incluye 20 capítulos organizados en cinco partes, que describo de manera general, destacando sus contenidos más importantes y mostrando algunas coincidencias entre las conclusiones y puntos de vista de los autores.

La primera parte del libro titulada "Globalización, ajuste estructural y panorama internacional y nacional de lucha contra la pobreza", incluye cinco trabajos de investigadores de Inglaterra y México. David Gordon y John Toye critican los programas de los organismos internacionales para reducir la pobreza, dominados en una medida importante por el Banco Mundial, y ponen énfasis en su orientación neoliberal y en su falta de éxito para sacar a los pobres de su condición; critican, asimismo, los métodos simplistas para medir la pobreza, que subestiman este fenómeno, así como las creencias tecnocráticas, poco humanitarias, de concentrar los recursos sólo entre los más pobres. En cuanto a los dos capítulos que ubican la pobreza en el contexto más general de la economía, el de José Luis Calva presenta una fuerte crítica al modelo neoliberal impuesto en México a partir de los años ochenta por sus efectos, entre otras cosas, sobre la planta productiva y el bienestar social, proponiendo algunos instrumentos viables de política económica que no significan regresar al modelo anterior, que también tuvo serios errores. Nora Lustig pone énfasis en la necesidad del crecimiento económico para reducir la pobreza, admitiendo ade-

* Comentario expuesto en El Colegio de México, el 26 de enero de 2005 en la presentación del libro.

** Profesora investigadora del Centro de Estudios Demográficos, Urbanos y Ambientales de El Colegio de México. Correo electrónico: mschtein@colmex.mx.

ESTUDIOS DEMOGRÁFICOS Y URBANOS, VOL. 21, NÚM. 1 (61), PP. 243-248 
más que ésta puede ser un obstáculo al crecimiento; para atacar la pobreza afirma que es necesario la inversión en capital humano (como en el programa Oportunidades) pero también en otros rubros de ayuda a los pobres, como los créditos, el apoyo tecnológico, etc. El trabajo de Araceli Damián cierra esta primera parte del libro con un análisis de la evolución de la pobreza en América Latina y México, que muestra el aumento general de la pobreza en la región, puntualizando asimismo que el mejoramiento en las condiciones de la educación no ha sido suficiente para reducir la pobreza, argumento que es retomado por otros autores, y en particular en la evaluación del programa mexicano Oportunidades. En el estudio que presenta para el caso de México, utilizando distintos métodos de medición de la pobreza, señala que ésta es más alta a fines del siglo Xx que al terminar los años sesenta.

En la segunda parte del volumen se abordan los "Modelos de bienestar social en centro y periferia", tema fundamental para ubicar las políticas sociales y en particular las de combate a la pobreza en el contexto de los diferentes paradigmas que se vislumbran detrás de las mismas. Tres de los cuatro autores de los capítulos de esta parte, comparten algunas críticas a los cambios que han implicado, sobre todo en América Latina, una mayor dependencia del mercado en la oferta de servicios sociales, una declinación de las políticas universales y la aplicación de políticas focalizadas hacia los más pobres. En el trabajo de Eduardo Bustelo de Argentina se argumenta, por ejemplo, que las reformas económicas neoliberales no han llevado, hacia comienzos del siglo XXI, a sentar las bases de un desarrollo que mejore el bienestar de la población y corrija la desigual distribución del ingreso y las disparidades sociales; apunta además que en el enfoque del capital social, tan utilizado por los organismos internacionales, las relaciones sociales están al servicio del mercado, mientras que en el paradigma que apoya el reforzamiento del Estado de Bienestar se ponía énfasis en la ciudadanía conformada por valores compartidos. Como dicen los coordinadores de este libro en la introducción, el autor no se aferra a una visión nostálgica pero plantea un nuevo concepto social histórico que tome como eje la igualdad. El trabajo de Evelyne Huber de Estados Unidos analiza la política social en América Latina en los años ochenta y noventa, refiriéndose de manera crítica a las limitaciones del modelo de seguridad social que prevaleció en décadas anteriores en los distintos países de esa región. Cuestiona severamente los resultados de las políticas neoliberales que generaron mayor desempleo, pobreza y disminución en la calidad de los servicios de educación y 
salud; asimismo objeta la eliminación del control de precios y de los subsidios a los productos básicos. En cuanto a los programas focalizados, esta autora afirma que el gasto fue mucho menor que el de los esquemas universales y aun cuando hubo un cierto incremento del gasto social y una caída de la pobreza en algunos países a principios de los noventa, no se lograron restablecer los niveles de pobreza anteriores -como ya lo había mostrado Araceli Damián para México en el trabajo ya mencionado-. Huber cuestiona también ciertas ideas difundidas por el Banco Mundial como que "el aumento de la inversión en capital humano reduce la pobreza y la desigualdad y que los esquemas universales desperdician dinero en la clase media y alta". Por último, comparando lo que ocurre en Europa y América Latina en el tema de las políticas sociales, considera que en Europa existen instituciones democráticas y grupos que defienden con mucho mas fuerza que en América Latina, el objetivo universalista y solidario de las políticas de protección social, tanto a través de algunos partidos políticos como de los sindicatos. A estos trabajos se agrega el de Vivianne Brachet sobre México, en el cual muestra los obstáculos que se han enfrentado para lograr un verdadero Estado de Bienestar, ya que su construcción se dio en contextos autoritarios e inestables que influyeron para que se presentara de manera fragmentada, inequitativa e incompleta. Después de pasar una revista crítica a diferentes políticas y programas que se aplicaron durante las últimas décadas, considera que las políticas de lucha contra la pobreza dividieron a los no pobres de ingresos modestos, que fueron recibiendo cada vez menos apoyos, de los pobres que también fueron excluidos de sus beneficios desde 1997 y de los extremadamente pobres que fueron objeto de programas focalizados.

Me parece que el capítulo de Felipe González, ex presidente de España, merece una reflexión separada de las demás ya que se trata de la aportación de un político y no de un estudioso de los temas que aquí se analizan, como es el caso de los demás autores. Si bien comparte algunas críticas que se hacen a la problemática situación latinoamericana y a las dificultades para mejorarla, su mensaje se centra en la necesidad de dejar de lado los fundamentalismos y la ideología, que muchas veces son un estorbo para hacer las cosas, refiriéndose concretamente a su posición como socialista pragmático que liberalizó la economía española y defendió el mercado, con muy buenos resultados, cuando dentro de la izquierda su defensa parecía un pecado mortal. Sin embargo es necesario aclarar que, como puede observarse en las diversas contribuciones que conforman este libro, muchas de las afir- 
maciones contra el neoliberalismo y sus estrategias con respecto a las políticas sociales y la pobreza, se apoyan en el análisis de los resultados de procesos y políticas concretas aplicadas en diferentes países.

La tercera parte del libro titulada "Experiencias de lucha contra la pobreza" incluye cinco trabajos. En el primero Janssen y Pachico discuten los programas de innovaciones agrícolas para disminuir la pobreza, a partir de argumentos teóricos y algunos ejemplos tanto de América Latina como de África, mientras en el segundo Óscar Fresneda estudia los logros y deficiencias del sistema de subsidios a la salud en Colombia. En cuanto a los análisis para México, Julio Boltvinik, Michelle Adatto y Agustín Escobar presentan y discuten el programa mexicano más importante de combate a la pobreza, Oportunidades. Adatto lo ubica dentro de los programas llamados "de transferencias monetarias condicionadas" ya que implican ciertos pagos a las familias seleccionadas, a través de procesos de focalización condicionados a la participación de esas familias en programas de salud, nutrición y asistencia de los niños a la escuela. En su capítulo Boltvinik señala que el programa de Progresa, hoy Oportunidades, que comenzó en 1997, pertenece al modelo liberal residual de bienestar social -que se explica en la segunda parte del libro-, y según el cual, para tener derecho a la asistencia hay que mostrar que se está en situación de necesidad. Además, como otros programas focalizados, Oportunidades tiene que hacer frente a los altos costos administrativos y muchas veces a la falta de veracidad de las respuestas de la población que es seleccionada para acceder al programa. El autor identifica problemas en cuanto al diseño del programa, ya que la forma como se dan los apoyos diferenciados aumenta las desigualdades entre los pobres, perjudicando a los hogares que no tienen miembros en edad de estudiar y a los más numerosos. Critica asimismo las evaluaciones realizadas en los últimos años ya que, por ejemplo, las recomendaciones emanadas de las mismas no han sido incorporadas al programa, además de que existe una cierta falta de objetividad en la manera de efectuarlas ya que la misma institución que lleva a cabo el programa, contrata a los evaluadores.

Esta tercera parte del libro comprende también una evaluación cualitativa del programa Oportunidades en su primera fase de expansión a zonas suburbanas, a cargo de Agustín Escobar. En ella, además de analizar la situación de la población en los componentes de educación, salud y alimentación, se evalúan los efectos del programa en la vivienda y el empleo. De sus interesantes conclusiones acerca de los impactos positivos y negativos del programa en la situación de las fa- 
milias seleccionadas, vale la pena destacar su afirmación de que la disponibilidad de empleos y el nivel salarial de los adultos no ha mejorado en las comunidades atendidas, por lo cual no ha disminuido la vulnerabilidad de los hogares beneficiados. A esto se agrega que, como se señalaba también en otros trabajos, se han observado situaciones muy graves dentro de las familias como consecuencia de que las mujeres son las que reciben los apoyos del programa (como separaciones conyugales o abandono de los hogares por parte de los hombres, quienes muchas veces han disminuido sus aportaciones al presupuesto familiar). Así, algunas conclusiones de los análisis más pormenorizados de este programa confirman las críticas generales que se presentan a este tipo de orientación de la política social.

La cuarta parte del volumen, "Una mirada global al futuro de la pobreza", incluye sólo un trabajo, el de Townsend y Gordon, que se ha querido destacar por incluir una serie de recomendaciones de carácter general para cambiar la situación actual. Estas recomendaciones abarcan desde la necesidad de establecer un umbral de pobreza válido internacionalmente hasta aplicar una serie de medidas para modificar la jerarquía de poder a nivel mundial, sobre todo a partir de cambios democráticos en los organismos internacionales, pasando por la propuesta de regresar a las políticas universales ya que las focalizadas han mostrado su incapacidad para disminuir o erradicar la pobreza. Aunque no queda muy claro cómo podrían llevarse a cabo estas transformaciones, nos ha parecido un esfuerzo válido e interesante llevar a cabo un ejercicio de propuestas como el que aquí se presenta.

El libro termina con una quinta parte denominada "Métodos de medición de la pobreza, un debate" con cuatro trabajos, de Boltvinik, Fresneda, Damián y Ringen, en los que se critican las limitaciones de los métodos tradicionales, se aportan nuevas propuestas a esas mediciones (como por ejemplo la medición de la pobreza de tiempo), y se hacen recomendaciones acerca de cómo considerar a los que resultan afectados por el problema de la pobreza (que no sólo serían los pobres sino también los que están en riesgo y son vulnerables a la pobreza, o los que entran y salen de ella). Creo que esta consideración es muy válida sobre todo si tomamos en cuenta el caso de Argentina, país que ha experimentado en los últimos años un cambio dramático en cuanto al porcentaje de pobres en la sociedad (que pasó en un corto lapso de 15 a 50\%), con la aparición del fenómeno de los llamados nuevos pobres, muchos de los cuales estaban seguramente en una situación 
de riesgo ya en años anteriores a la última crisis.

Por todo lo comentado recomiendo ampliamente la lectura de este importante libro, no sólo a los que estudian el tema de la pobreza y las políticas sociales sino también a todos los interesados en la problemática social, actual y futura, de nuestro continente. 